\title{
PEOPLE AND ORGANIZATIONAL CULTURE: A PROFILE COMPARISON APPROACH TO ASSESSING PERSON-ORGANIZATION FIT
}

\author{
CHARLES A. O'REILLY III \\ University of California, Berkeley \\ JENNIFER CHATMAN \\ Northwestern University \\ DAVID F. CALDWELL \\ Santa Clara University
}

\begin{abstract}
This article brings together three current themes in organizational behavior: (1) a renewed interest in assessing person-situation interactional constructs, (2) the quantitative assessment of organizational culture, and (3) the application of "Q-sort," or template-matching, approaches to assessing person-situation interactions. Using longitudinal data from accountants and M.B.A. students and cross-sectional data from employees of government agencies and public accounting firms, we developed and validated an instrument for assessing personorganization fit, the Organizational Culture Profile (OCP). Results suggest that the dimensionality of individual preferences for organizational cultures and the existence of these cultures are interpretable. Further, person-organization fit predicts job satisfaction and organizational commitment a year after fit was measured and actual turnover after two years. This evidence attests to the importance of understanding the fit between individuals' preferences and organizational cultures.
\end{abstract}

The notion of organizational culture has been important in the study of organizational behavior for the past decade (e.g., Barley, Meyer, \& Gash, 1988; O'Reilly, 1989; Smircich, 1983). In spite of disagreements over some elements of definition and measurement, researchers seem to agree that culture may be an important factor in determining how well an individual fits an organizational context (e.g., Kilmann, Saxton, \& Serpa, 1986; Schein, 1985). Implicit in writing on this theme is a logic of person-culture fit fundamentally drawn from an interactional psychology perspective in which aspects of both individual and situation combine to influence a focal individual's response to a given situation (e.g., Chatman, 1989; Schneider, 1987; Terborg, 1981). In this regard, aspects of individuals, such as values and

The authors gratefully acknowledge the research support of the Institute of Industrial Relations and the Institute for Personality Assessment and Research at the University of California, Berkeley. We also thank John Sheridan and Blair Sheppard for providing data access. 
expectations, interact with facets of situations, such as incentive systems and norms, to affect the individuals' attitudinal and behavioral responses. As with similar fit theories of careers (Holland, 1985), job choice (Hackman \& Oldham, 1980), work adjustment (Lofquist \& Dawis, 1969), and organizational climate (Joyce \& Slocum, 1984), the validation of the construct of person-culture fit rests on the ability to assess relevant aspects of both person and culture. This measurement problem is a significant and sometimes controversial issue (Keon, Latack, \& Wanous, 1982; Rousseau, 1990) - one that is at the center of the person-situation debate, that is, the controversy over the degree to which personality or context variables explain attitudes and behavior (Bem \& Allen, 1974; Davis-Blake \& Pfeffer, 1989; Kenrick \& Funder, 1988). The purpose of this research was to examine person-culture fit and its implications for work attitudes and behavior. We draw on recent developments in the applications of Q-sort, or template-matching, ${ }^{1}$ approaches to resolve some of the measurement issues that have hindered previous research on fit (Bem \& Funder, 1978; Block, Block, \& Morrison, 1981; Caldwell \& O'Reilly, 1990).

\section{THEORETICAL BACKGROUND}

\section{Person-Situation Fit}

The general notion of fit, or congruence, has long been important in psychology and organizational behavior (Nadler \& Tushman, 1980). In studying person-situation fit, organizational behavior researchers have typically taken one of two broad paths. One has led to exploration of the interaction of individual characteristics and broad occupational attributes, the other to exploration of the fit between specific characteristics of an organization and the people in it. Examples of the second approach range from studying the match of individual skills to job requirements to studying the relationship between individual characteristics and organizational climate (e.g., Downey, Hellriegel, \& Slocum, 1975). For example, the two major theories of vocational choice (Holland, 1985; Super, 1957) both postulate that an individual will select a career or occupation that is similar to or that fits with that person's self-concept. Empirical results have typically supported the hypothesis that congruence between individuals' personalities and the demands of their occupations are associated with positive affect (Mount \& Muchinsky, 1978; Spokane, 1985) and a high likelihood of their staying in their jobs (Meir \& Hasson, 1982). A similar logic characterizes a series of studies of work adjustment conducted by Lofquist and Dawis (1969). For

${ }^{1}$ Q-methodology (Stephenson, 1953) is a well-established assessment technique. In a typical Q-sort procedure, the individual is presented with a large number of statements or characteristics and asked to sort the items into categories (normally nine) according to some criterion (usually the extent to which the item is characteristic of the individual). Constraints are typically imposed to force respondents to place fewer items in the extreme categories and more items in the middle categories. 
instance, they proposed that satisfaction results from "a harmonious relationship between the individual and his environment, suitability of the individual to the environment and vice versa" (1969: 45). Tom (1971) recast this notion of person-situation complementarity to focus on personorganization fit. He studied the role of personality and organizational images in the recruiting process and found that the greater the similarity between an individual's self-concept and his or her image of an organization, the more that individual preferred that organization. In a similar vein, Keon and colleagues (1982) found that individuals with a positive self-image sought to enter graduate schools with positive organizational images. Other studies have reported generally consistent findings (e.g., Graham, 1976).

More recent studies of early career adjustment and person-job fit have also invoked notions of congruence. For example, in a programmatic effort, Wanous and his colleagues showed how an accurate understanding of job requirements can enhance a person's adjustment to a job (Wanous, 1977). Similarly, the congruence between a person and a job have embodied notions of fit (e.g., O'Reilly, 1977): the degree to which individuals are suited to a job depends on their motives and needs and the job's requirements (Hackman \& Oldham, 1980).

The cited studies and more general studies of person-situation interactions (e.g., Diener, Larsen, \& Emmons, 1984; Pervin, 1968) rest on the premise that positive responses will occur when individuals fit or match the requirements of a situation. Although broadly used and intuitively compelling, the person-situation framework has spawned a number of disagreements. For example, a recent issue of the Academy of Management Review (1989, vol. 14, no. 3) contained articles dealing with those controversies. One important question raised is how fit should be defined (Chatman, 1989).

The definition of fit remains a critical and largely unanswered question (Rynes \& Gerhart, 1990). For instance, most studies of person-situation fit in organizations have used normative measures of personality to assess individual characteristics and relatively broad classifications of tasks, occupations, or jobs to characterize situations. Thus, people are described with one language, or set of characteristics, and situations with a totally different language. This failure to describe people and situations along commensurate dimensions limits scholars' ability to develop a coherent theory of personsituation interactions (Graham, 1976; Pervin, 1968; Springfield, 1988) and makes it difficult to determine the real impact of person-situation effects (Terborg, 1981). Further, the use of a very limited set of descriptions of person and situation may make the detection of any true interaction effect difficult. Davis-Blake and Pfeffer, for example, observed that similar jobs in different firms may vary greatly and concluded that the "measurement of job characteristics requires moving beyond crude occupational surrogates to measures which actually reflect the characteristics of a particular job as it is structured in a particular organizational setting" (1989: 394). A similar criticism can be made of the extant treatments of personality, in which most researchers have relied on a few normative measures that may not only fail 
to describe individuals adequately but may also assess personality characteristics not relevant to the people or situations under study (O'Reilly, Caldwell, \& Mirabile, 1990; Weiss \& Adler, 1984). Thus, although suggestive, previous research has generally failed to describe people and situations in a comprehensive manner along commensurate and relevant dimensions. This failure has hindered the development and empirical assessment of coherent theories of person-situation interaction.

Recent work in interactional psychology has begun to identify the characteristics of effective techniques for addressing person-situation effects. Bem and Funder (1978) argued that, in addition to providing comprehensive measurements, effective techniques for assessing persons and situations should allow for holistic comparisons across multiple dimensions. Such an approach can be thought of as "semi-idiographic" in that it is idiographic (i.e., compares the relative strength of attributes within a single individual) with respect to individual attributes but permits comparisons of personsituations (Luthans \& Davis, 1982; Springfield, 1988). Since any given trait dimension will not be applicable to all individuals, we want to be able to select only those personological variables that are pertinent to a focal individual. Doing so requires an idiographic approach rather than a nomothetic one in which all individuals are rated in terms of a given attribute (Lamiell, 1981). The difficulty, however, with an idiographic approach is that it isn't clear what to do once a rating has been made. What is then needed is to be able to compare individuals even though descriptors may be differentially relevant to them.

Using "Q-methodology" (Stephenson, 1953), Bem and Allen (1974) developed a template-matching technique to accommodate this dual concern with relevance and comparability. This approach focuses on the salience and configuration of variables within a person rather than on the relative standing of persons across each variable. Since not all characteristics apply to all people and since what differentiates people from each other is the set of traits salient to each individual, an assessment of person-situation fit must permit such idiographic measurement of each person while also allowing comparisons across situations. Such an approach requires a large number of items or descriptors that comprehensively describe individuals and are relevant to particular situations. For instance, Bem and Funder (1978) created a 100-item profile of the ideal person for successful performance in an array of specific situations. How well individuals might do in a situation was predicted by how well they matched the ideal person-in-situation profile. Thus, rather than comparing a person and situation on a few dimensions, an appropriate person-situation investigation would attempt to determine the overall fit of the person to the set of relevant situational attributes.

Drawing on the Q-sort technique used for template matching, Caldwell and O'Reilly (1990) and O'Reilly and colleagues (1990) developed a profilematching process to assess person-job fit. Using a structured interview job analysis with job incumbents and experts, they first developed a comprehensive set of competencies required for successful job performance. This 
set (typically 60-90 items) was then used to construct a consensus profile of the job. Individual profiles were then obtained by using peers and superiors as assessors. Person-job fit was measured by correlating the two profiles. Results of a series of studies have shown that person-job fit predicts performance, satisfaction, and turnover across a variety of jobs. Like template matching (Bem \& Funder, 1978), the profile comparison process comprehensively assesses individuals and situations using a common language, allows for the ipsative measurement of individual characteristics by arraying attributes in terms of their salience to the individual, and provides a direct measure of person-situation fit. The profile comparison process goes beyond template matching by using items that are highly specific to a target situation and equally relevant to a person and a situation. Thus, the application of a Q-sort technique appears to be a useful way to obtain semi-idiographic assessments of fit and offers a way to resolve a number of the measurement problems that have characterized earlier studies of person-situation interaction.

\section{Person-Culture Fit}

Although a number of earlier studies have explored the general notion of person-organization fit (e.g., Graham, 1976; Joyce \& Slocum, 1984; Tom, 1971), more recent interest has centered on the idea that organizations have cultures that are more or less attractive to certain types of individuals (e.g., Wilkins \& Ouchi, 1983). As Barley and colleagues (1988) noted, the concept of organizational culture has a long history, dating to early sociological studies (e.g., Gouldner, 1954; Selznick, 1949). Only recently, however, has the term "organizational culture" become prominent.

Drawing on theories from anthropology, sociology, and social psychology, researchers have made a number of efforts to understand the behavior of individuals and groups in organizations using cultural concepts such as semiotics, rituals, ceremonies, stories, and language (e.g., Ouchi \& Wilkins, 1985; Smircich, 1983; Swidler, 1986; Trice \& Beyer, 1984). This process has generated a series of debates over issues such as the definition of "culture," the appropriate methodology for investigating it, and the proper level of analysis for its study. Barley (1983) pointed out that all studies of culture, whatever their theoretical origin, use reasonably similar terms and constructs. Differences exist among researchers in how objective or subjective, conscious or unconscious their use of these terms and constructs is and in what they see as appropriate elements to study. Typically, researchers have agreed that culture can be thought of as a set of cognitions shared by members of a social unit (e.g., Geertz, 1973; Smircich, 1983). Rousseau (1990) provided an excellent description of the common elements in such sets and suggested a framework including fundamental assumptions, values, behavioral norms and expectations, and larger patterns of behavior. Research on culture usually begins with a set of values and assumptions (Enz, 1988; Martin \& Siehl, 1983; Schein, 1985; Weiner, 1988). These values, whether conscious or unconscious, typically act as the defining elements 
around which norms, symbols, rituals, and other cultural activities revolve. Thus, Parsons argued that a cultural tradition emerges around values, defined as elements "of a shared symbolic system which serves as a criterion or standard for selection among the alternatives of orientation which are intrinsically open in a situation" (1951: 11-12). Rokeach offered a very similar definition, proposing that "a value is an enduring belief that a specific mode of conduct or end-state of existence is personally or socially preferable to an opposite or converse mode of conduct or end-state of existence" (1973: 5). In this vein, basic values may be thought of as internalized normative beliefs that can guide behavior. When a social unit's members share values, they may form the basis for social expectations or norms. Should these be even more widely shared throughout a larger social grouping, an organizational culture or value system may exist. Thus, researchers who investigate culture by focusing on norms (e.g., Cooke \& Rousseau, 1988; Harrison \& Carroll, 1991; O'Reilly, 1989) are studying social expectations that are based on underlying values. Others who study culture through rituals, stories, or myths (e.g., Louis, 1983; Martin \& Siehl, 1983; Trice \& Beyer, 1984) are examining phenotypic outcroppings that reflect underlying beliefs and values.

The pervasiveness and importance of values in organizational culture are fundamentally linked to the psychological process of identity formation in which individuals appear to seek a social identity that provides meaning and connectedness (Ashforth \& Mael, 1989). A substantial body of research has shown that individuals tend to classify themselves into social categories, such as gender, race, ethnicity, and organizational affiliation, and to use those categories to define themselves. For instance, people appear particularly able to discriminate between in-groups and out-groups and to be attracted to those seen as similar to themselves (Brewer, 1979; Moreland, 1985). Drawing on underlying values, individuals may manage their lives in ways that help them choose congruent roles, occupations, and even organizations (Albert \& Whetten, 1985; Sampson, 1978; Stryker \& Serpe, 1982). Schneider (1987) proposed that individuals may be attracted to organizations they perceive as having values similar to their own. In addition, organizations attempt to select recruits who are likely to share their values. New entrants are then further socialized and assimilated, and those who don't fit leave. Thus, basic individual values or preferences for certain modes of conduct are expressed in organizational choices and then reinforced within organizational contexts. Just as research has shown that similar backgrounds, attitudes, and experience can increase liking between individuals (Tsui \& O'Reilly, 1989), it may be that organizations that manifest and reward characteristic outcomes and behaviors will be more or less attractive to different types of people. Values provide the starting point, with the joint processes of selection and socialization acting as complementary means to insure person-organization fit (Chatman, 1988). Thus, congruency between an individual's values and those of an organization may be at the crux of person-culture fit. 


\section{The Assessment of Person-Culture Fit}

There are some fundamental areas of agreement in the definition of culture, but less agreement exists about its measurement. As Rousseau noted at the very outset of her review, "Quantitative assessment of culture is controversial" (1990: 1). She discussed how advocates of qualitative methods for studying culture have argued that much of what constitutes a culture may be a unique social construction of reality, perhaps unconscious on the part of the culture's members (e.g., Schein, 1985; Smircich, 1983). Acknowledging that some aspects of organizational culture may not be easily accessible, Rousseau also asserted that certain dimensions of culture may be appropriately studied using quantitative methods, indeed suggesting that quantitative assessments offer an opportunity to understand the systematic effects of culture on individual behavior.

One way to assess culture quantitatively is to focus on the central values that may be important to an individual's self-concept or identity as well as relevant to an organization's central value system. Weiner suggested this perspective, noting that "when a number of key or pivotal values concerning organization-related behaviors and state-of-affairs are shared across units and levels - by members of an organization, a central value system is said to exist" (1988: 535). To characterize an organization's culture in terms of its central values requires first that the range of relevant values be identified and then that an assessment be made of how much intensity and consensus there is among organizational members about those values (Enz, 1988; Saffold, 1988). O'Reilly (1989), drawing on earlier research on measuring norms, noted two important characteristics of strong cultures. One is intensity on the part of organization members, that is, displaying approval or disapproval to those who act in certain ways; the second is the presence of crystallization, or widespread agreement on values, among members. If there is no substantial agreement that a limited set of values is important in a social unit, a strong culture cannot be said to exist. If there is strong and widespread agreement about the salience and importance of specific values, a central value system or unit culture may exist.

Much previous research has suggested that person-culture fit increases commitment, satisfaction, and performance, but very little empirical research on these relationships has been done. The general research question examined here was the following: To what extent is person-culture fit associated with individual commitment, satisfaction, and longevity with an organization (Holland, 1985; Meir \& Hasson, 1982; Mount \& Muchinsky, 1978)? We expected to find that high levels of person-culture fit would be positively associated with those outcomes.

Addressing that question required two types of analyses. First, we needed to demonstrate that preferences individuals have for organizational cultures are comparable to cultures that exist. Second, the relationship between individual preferences and organizational culture needed to be assessed across a broad range of values. Therefore, we tested our general re- 
search question by developing a method of assessing culture based on the extant values of organizations and measuring person-culture fit through a semi-idiographic technique based on the profile comparison process (Caldwell \& O’Reilly, 1990; O’Reilly et al., 1990).

\section{METHODS}

\section{Overview}

To investigate person-culture fit, we developed an instrument we called the Organizational Culture Profile (OCP). This instrument contains a set of value statements that can be used to idiographically assess both the extent to which certain values characterize a target organization and an individual's preference for that particular configuration of values. Person-culture fit can be calculated by correlating the profile of organizational values with the profile of the individual's preferences.

In a set of related investigations using multiple sets of respondents, we explored the characteristics of the OCP and demonstrated its ability to assess both organizations and people. In addition, we explored the relationship between preferences for organizational values and individual personality variables. Finally, we used the OCP to assess person-culture fit and test for the relationship between fit and work-related outcomes.

\section{Development and Use of the Organizational Culture Profile}

The OCP was developed and used to measure person-organization fit. The approach to its development followed Caldwell and O'Reilly (1990). The OCP contains 54 value statements that can generically capture individual and organizational values. Following the general procedure for generating Q-sort profiles (Block, 1978), we had respondents sort the 54 items into nine categories, ranging, for instance, from most to least desirable or from most to least characteristic, and to put a specified number of statements in each category; the required item-category pattern is 2-4-6-9-12-9-6-4-2. Fewer items are required at the extremes than in the central, more neutral categories. The question respondents were asked to keep in mind while sorting the deck varied according to whether they were describing their own preferences or the value system or culture of a focal organization. To develop a profile of an organization's culture, we instructed respondents familiar with the organization to sort the 54 value statements according to the extent to which the items were characteristic of the organization. For individual preferences, individuals were asked to sort according to their personal preferences for each value in their ideal organization. With this procedure, separate groups of individuals can be used to assess a firm's culture and provide ratings of preferences. The degree to which the organization's values are consistently shared can be investigated by the intercorrelation among raters using a variation of the Spearman-Brown general prophecy formula (Nunnally, 1978). A more complete description of the development and general use of the OCP follows. 
Step 1-Describing organizational values. The set of value statements was developed on the basis of an extensive review of academic and practitioner-oriented writings on organizational values and culture (cf. Davis, 1984; Deal \& Kennedy, 1982; Kilmann, 1984; Ouchi, 1981; Peters \& Waterman, 1982; Schein, 1985). The purpose of this review was to identify a comprehensive set of values that could be used to characterize both individuals and organizations. An attempt was made to identify items that (1) could be used to describe any person or organization, (2) would not be equally characteristic of all people or organizations, and (3) would be easy to understand.

The initial pool of items consisted of over 110 items. For the final set, we used four criteria: (1) generality - an item should be relevant to any type of organization, regardless of industry, size, and composition; (2) discriminability - no item should reside in the same category for all organizations; (3) readability - the items should be easily understandable to facilitate their having commonly shared meanings; and (4) nonredundancy - the items should have distinct enough meanings that they could not substitute for one another consistently. Therefore, in addition to the literature search, we made a systematic empirical check to insure that the items met those criteria.

We asked 38 undergraduates participating in a vocational interest feedback program, all seniors majoring in business administration, and four faculty members to screen the 110 items, identifying items that were redundant, irrelevant, or difficult to understand. They were also asked to identify any unincluded items that would be important descriptors of an organization's culture. We made a similar check with respondents from a set of accounting firms. After several iterations, we obtained a final set of 54 value-based characteristics, which are listed in the Appendix.

Step 2-Assessing characteristics of firms. To obtain profiles of the cultures of firms, we identified sets of key informants with broad experience and asked them to sort the 54 items in terms of how characteristic each was of their organization's culture. Respondents received the following definition and instructions: "Important values may be expressed in the form of norms or shared expectations about what's important, how to behave or what attitudes are appropriate. Please sort the 54 values into a row of nine categories, placing at one end of the row those cards that you consider to be the most characteristic aspects of the culture of your organization, and at the other end those cards that you believe to be the least characteristic. ..."

To study eight accounting firms, Chatman (1988) used an average of 16 accountants per firm with an average tenure of eight years. She constructed separate firm profiles by averaging the responses of the raters within each firm. The extent to which individuals in a firm described it in a consistent way was assessed through a variation of the Spearman-Brown general prophecy formula. The eight profiles showed substantial reliability, with an average alpha of .88 , representing a range of .84 to .90 , indicating relatively high levels of agreement among the raters in each firm. The similarity of the cultures of the eight firms was assessed by correlating the overall firm pro- 
files with one another. These correlations ranged from .29 to .85, suggesting substantial variability in the extent to which any two firms had similar cultures. Reliabilities for the government agency and other accounting firms used in the studies reported here were also high.

Step 3-Assessing individual preferences. To assess individual preferences for organizational cultures, respondents were asked to sort the 54-item deck into the nine categories by responding to the question, "How important is it for this characteristic to be a part of the organization you work for?" The answers ranged from "most desirable" to "most undesirable." To assess the test-retest reliability, or stability, of such preferences, we had 16 M.B.A.degree candidates complete Q-sorts 12 months apart. The instructions for these respondents were identical to those for the other groups providing data for the overall effort reported here. Correlations over the year averaged .73, suggesting a high stability of preferences. To investigate possible social desirability bias in the sorts, we gave eight doctoral students at the same university a description and definition of what constitutes social desirability bias and asked them to sort the 54 items in the most socially desirable way. Such biases, if undetected, could limit the variability of the profiles. In order to minimize such limitation, we cast all items in the OCP in socially neutral or slightly positive terms. This social desirability profile was then compared to firm profiles for the eight accounting firms. No evidence of social desirability bias emerged - organizations' members did not appear to be sorting the OCP in a way calculated to make their firms look like good places to work.

Step 4-Calculating the person-organization fit score. We calculated a person-organization fit score for each individual by correlating the individual preference profile with the profile of the firm for which the person worked. More thorough descriptions of this approach to assessing fit appear in Chatman (1989) and in Caldwell and O'Reilly (1990).

\section{Respondents}

Data to develop and test the OCP were obtained from five separate groups of respondents. The first consisted of 131 first-year M.B.A. students at a west coast university voluntarily participating in a managerial and personality assessment project (group 1). They completed the OCP to assess their preferences for organization values and provided substantial personality data, completing the Adjective Check List (Gough \& Heilbrun, 1980), a well-developed and widely used measure of personality. Men comprised 57 percent of group 1, women 43 percent; the average age was 27.7 and the average years of work experience was 3.2 . We used this group in two ways, first in combination with other groups to assess the structure of individual preferences for organizational values, and second, to investigate the relationship between personality and preferences for organizational cultures.

A second group of 93 M.B.A. students at a midwestern university provided OCP data on individual culture preferences (group 2). Men comprised 54 percent of this group; the average age was 26 and the average number of 
years of work experience was two. We combined this group with others to assess the structure of individual preferences.

The third group of respondents was part of a longitudinal study that tracked new accountants as they entered and proceeded through their first two years in west coast offices of eight of the largest U.S. public accounting firms (Chatman, 1988). In each of the eight firms, most or all of the accountants hired in 1986 into the audit function participated in the study; for all the firms, there were 171 respondents, representing 84 percent of the eligible employees (the mean per firm was 22 , s.d. $=5$ ). The demographic characteristics of group 3 were as follows: 47 percent were men; the average age was 24 in the fall of 1986; all had bachelor's degrees; and 25 percent had master's degrees. At the time of data collection, salaries were nearly identical across the eight firms $(\bar{x}=\$ 21,500$, s.d. $=\$ 1,000)$, and all respondents entered their firms with the title of staff accountant.

These individuals provided data on their preferences by completing the OCP. In addition, we surveyed them approximately 12 months later regarding their job satisfaction, organizational commitment, and intent to leave. A measure of actual turnover was obtained approximately 24 months after the OCP data were collected. Data from this group were used in two ways. First, we combined their OCP responses with those obtained from the first two groups to assess the structure of individual preferences for organizational values. Second, we correlated individual OCP data with firm-level measures of corporate culture (obtained from a fourth group of respondents) to provide a measure of person-culture fit. This fit score was related to the individual outcome variables of job satisfaction, commitment, intent to leave, and actual turnover.

Data were also obtained from 128 senior accountants employed by the eight firms taking part in the longitudinal study of new accountants. Approximately 18 individuals completed the OCP for each firm, describing the pattern of values that characterized the organization. All these informants had at least two years experience in the firm. We developed an overall profile of the culture of each firm by averaging the individual responses. There was a high level of agreement among the members of each firm, as shown by Spearman-Brown coefficients ranging from .84 to .90. We used data from this sample to generate the aggregate profiles describing the culture of each of the eight accounting firms. These were then used to calculate the person-culture fit scores for the newly hired accountants.

The fourth group of respondents consisted of 96 certified public accountants from six offices of major accounting firms in the west central United States. Of group 4, 63 percent were men; the group's average tenure was 85 months and 55 percent were over 30 years of age. These respondents provided assessments of firm culture. We combined these data with data from a fifth group of respondents to analyze the structure of OCP descriptions of firm cultures.

The fifth group consisted of 730 middle-level managers employed by a government agency who were attending a continuing management develop- 
ment program at an east coast university. In group 5, 88 percent of the respondents were men; the average age was 45.9 and the average tenure with the employing agency was 21.4 years. All described the values of their organization by completing the OCP. We combined these data with those from group 4 to analyze the structure of the values defining corporate culture.

\section{Measures}

To test the general hypothesis that person-organization fit is related to work outcomes, we measured a number of other variables:

Person-organization fit. The new accountants in group 3 sorted the items in the OCP in terms of their own preferences for organizational culture. The senior accountants in group 3 sorted the items in terms of how descriptive they were of their firms. Thus, we developed a profile of the culture of each firm and calculated person-organization fit by correlating the rankings of the set of 54 individual preferences obtained from the new accountants with the rankings of the 54 values obtained from the senior accountants in the firm that employed them. The person-organization fit correlations ranged from -.36 to +.62 .

To establish the predictive validity of person-organization fit, follow-up data were collected from the entry-level accountants, through surveying respondents from seven of the eight firms about one year after the initial data collection. Because of a delay in collecting initial data at the eighth firm, it was impossible to survey the individuals at this firm, although the firm provided information about turnover. This limitation reduced the potential number of respondents in the second survey to 144. Of that number, 6 had left their firms and 2 were on extended leaves of absence at the time of the follow-up survey. Eligible respondents returned a total of 127 surveys, yielding a response rate of about 92 percent. Questions in the survey used related to commitment, job satisfaction, and intent to leave.

Organizational commitment. Commitment was measured using O'Reilly and Chatman's (1986) 12-item scale. A principal components analysis with varimax rotation yielded two factors. One factor, normative commitment, was defined by eight items representing commitment based on an acceptance of an organization's values. The second factor, instrumental commitment, was defined by four items describing commitment based on exchange, or in response to specific rewards. These factors are consistent with recent findings (Caldwell, Chatman, \& O'Reilly, 1990). We calculated separate factor scores for normative and instrumental commitment and used them in subsequent analyses.

Job satisfaction. Overall satisfaction with a job was measured using the single-item Faces Scale (Kunin, 1955). Recent research has shown this scale to be the most balanced job satisfaction measure in terms of capturing positive and negative affect and cognitions (Brief \& Roberson, 1989).

Intent to leave. Intentions of leaving an organization were measured with four 7-point Likert-type questions: (1) "To what extent would you prefer another more ideal job than the one you now work in?" (2) "To what 
extent have you thought seriously about changing organizations since beginning to work here?" (3) "How long do you intend to remain with this organization?" and (4) "If you have your own way, will you be working for this organization three years from now?" Since a principal components analysis of the questions yielded a single factor, we calculated one factor score to measure intent to leave.

Turnover. Approximately one year after the administration of the second survey and two years after person-organization fit was measured, each of the eight firms provided a list of individuals who had left and the dates of their departures. Although responses to the commitment, satisfaction, and intent-to-leave questions were available from only 127 individuals, actual turnover data were available for all the original respondents. Of the 171 individuals for whom person-organization fit scores were available, about 28 percent $(N=47)$ had left their firms in the two-year period.

Control variables. Since the initial person-organization fit data were obtained very soon after individuals joined their firms, during what is potentially a key time in shaping future attitudes (e.g., Louis, 1980), we controlled tenure with a firm at the time initial data were collected $(\bar{x}=19$ days, s.d. = 27). Age and gender were also used as control variables. Although respondents differed in the degrees they had obtained, we did not use degree as a control because all these individuals had identical jobs and because the quality of the programs from which they had graduated varied substantially. It therefore seemed that issues degree might normally index, such as expectations and career prospects, would not be related to that variable for the individuals studied.

\section{RESULTS}

Although the initial development of the OCP showed good internal and test-retest reliability, validity remained a major concern; did the OCP discriminate among individuals and organizations in terms of their central value systems and did the measure of individual-culture fit have predictive validity? To test those questions, we used two general types of analyses. First, we conducted separate factor analyses of the individual (Table 1) and organizational profiles (Table 3 ) to examine the dimensionality underlying the OCP. To be useful, the dimensions of individual preferences and organizational cultures should be comparable. Evidence of such comparability would indicate that the types of cultures individuals indicate they want are generally equivalent to the cultures organizations offer, and lack of comparability would reduce the meaningfulness of person-organization fit. In addition, evidence that the individual dimensions of culture are associated with characteristically different personality types would suggest that the underlying factors are psychologically meaningful (Table 2). In addition to seeking evidence of discriminant validity, we used a second set of analyses based on person-organization fit scores to predict satisfaction, commitment, and tenure (Tables 4-6). Taken together, the results of these analyses dem- 


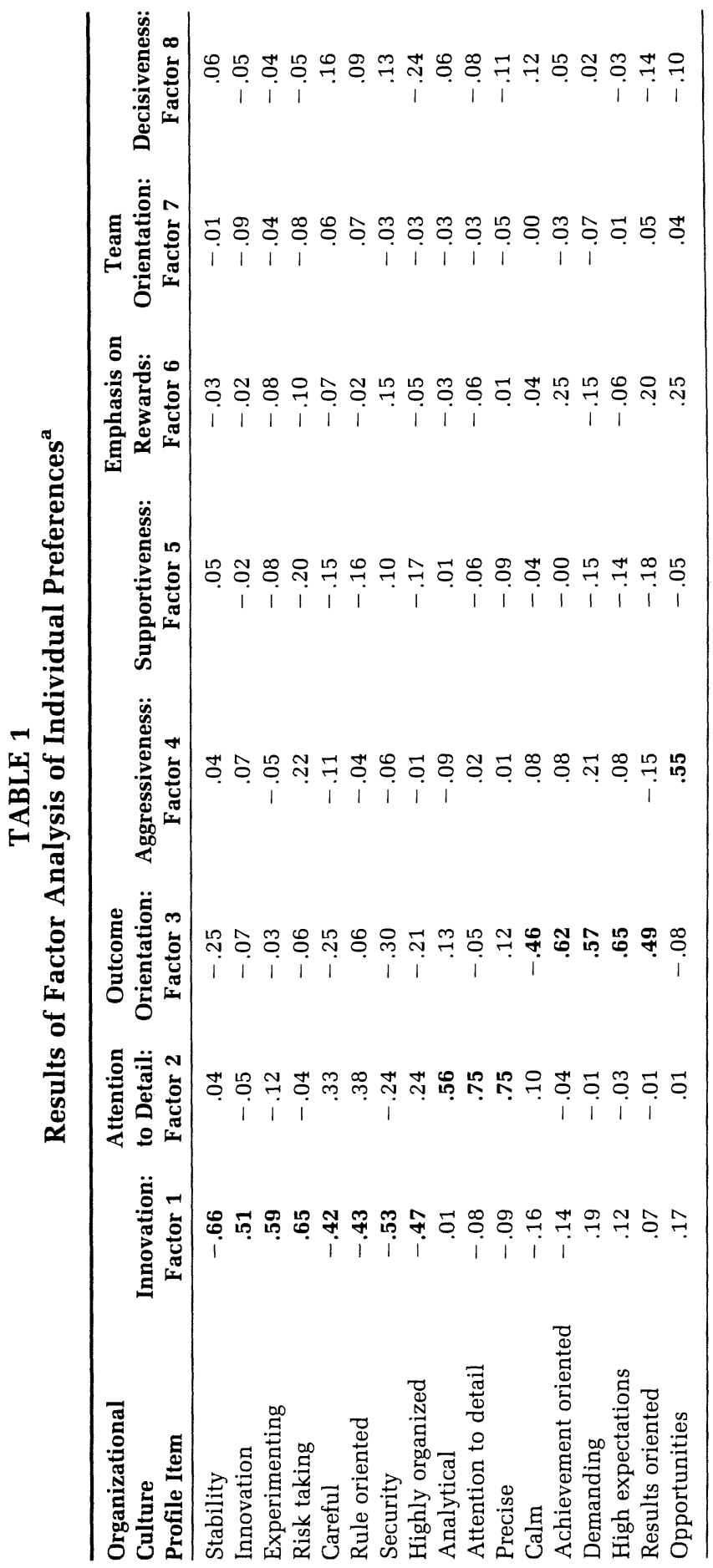




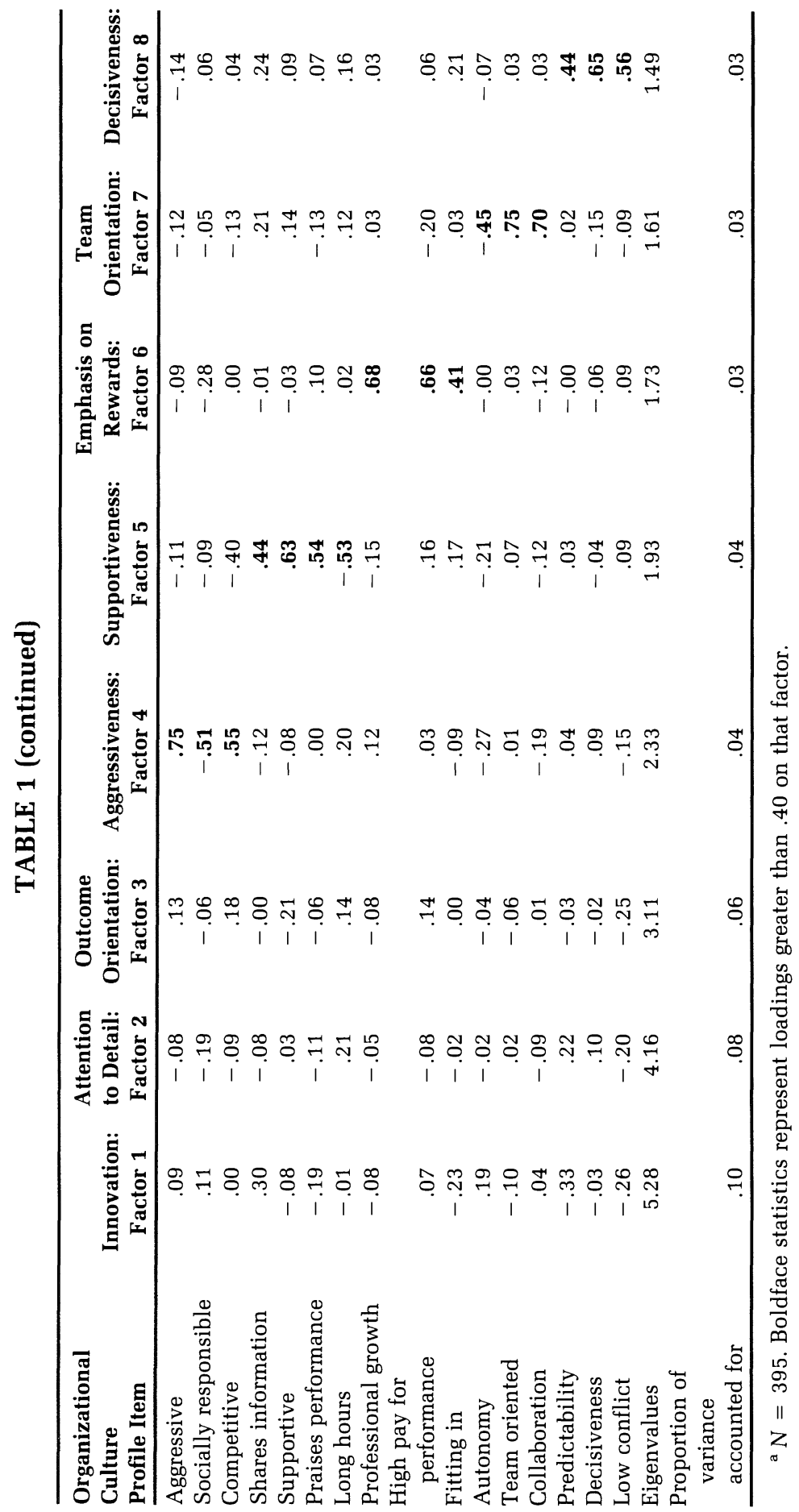


onstrate that person-organization fit possesses predictive validity and is organizationally useful.

\section{Discriminant Validity and the Factor Structure of the Organizational Culture Profile}

Recall that each respondent was asked to sort the 54 items in the OCP into nine categories ranging from most to least desirable according to how important it was for the person that the characteristic represented be a part of an organization's culture. Following Block (1978), we analyzed data from the two groups of M.B.A. students and the new accountants (groups 1,2, and $3, N=395$ ) using principal components analysis with varimax rotation. Results of an analysis of all 54 items revealed 33 items with loadings of greater than .40 on a single factor. Table 1 shows results; items with significant cross-loadings are not reported.

From a scree test, eight interpretable factors with eigenvalues greater than 1.0 and defined by at least three items emerged. This pattern shows that an organization's culture can be characterized by innovation and risk taking (factor 1), attention to detail (factor 2), orientation toward outcomes or results (factor 3), aggressiveness and competitiveness (factor 4), supportiveness (factor 5), emphasis on growth and rewards (factor 6), a collaborative and team orientation (factor 7), and decisiveness (factor 8). These eight orthogonal factors are unambiguously defined. In general, they approximate many of the dimensions to which the qualitative literature on culture has often referred (e.g., Deal \& Kennedy, 1982; Peters \& Waterman, 1982).

It would support the reasonableness of those dimensions if different types of individuals reported preferences for cultures differing along the dimensions. To investigate, we computed factor scores for the west coast M.B.A. students (group $1, N=131$ ). We then correlated those scores with a very well-developed measure of normal personality, the Adjective Check List (Gough \& Heilbrun, 1980). The instrument, which provides multiple measures of the strength of motives such as affiliation, aggression, and achievement, has demonstrated substantial reliability and validity, with a median scale alpha of .76. One indication of the validity of the OCP dimensions would be the emergence of distinctive preferences for different organizational cultures among respondents with characteristically different personality attributes. Table 2 presents the correlations among a set of Adjective Check List measures and the eight OCP factor scores.

Although we do not report specific hypotheses here, good support for seven of the eight factors can be seen in the form of easily interpretable patterns of personality and cultural preferences. For instance, individuals with high needs for achievement show a significant preference for aggressive, outcome-oriented cultures. Respondents with high needs for autonomy show a preference for innovative cultures and negativity toward those characterized by an emphasis on supportiveness and teamwork. Only the detailorientation factor, defined by a preference for precision, analysis, and attention to detail, shows no correlation with any personality dimension. This 


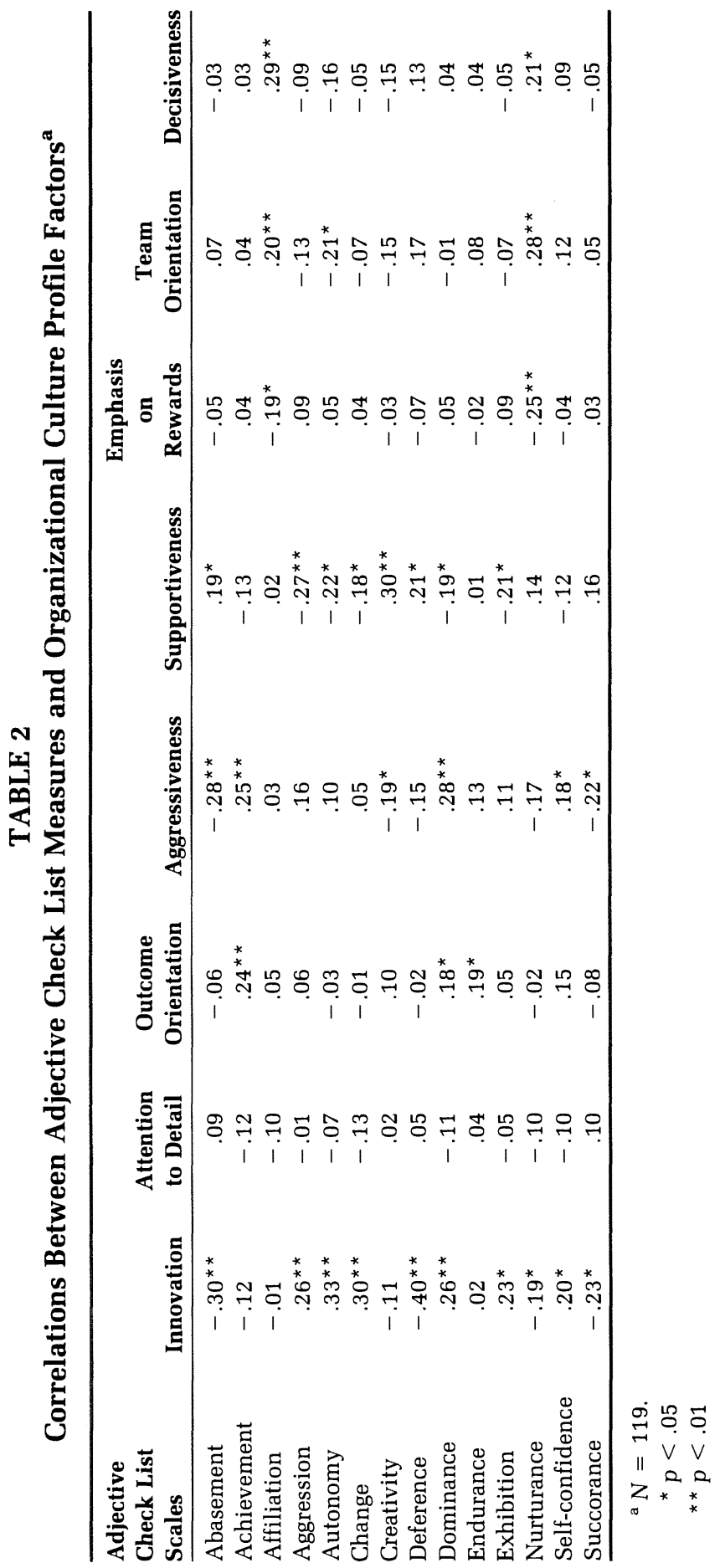


absence may reflect the fact that the Adjective Check List does not contain any assessment of obsessive-compulsive tendencies. Overall, the results suggest that the dimensions underlying individual preferences for distinctive cultures are meaningfully associated with characteristic differences in underlying personality variables.

Additional important questions are whether the OCP reflects meaningful organizational dimensions and whether the individual and organizational matrices are similar. To address those issues, we had 826 respondents from the government agency and six accounting firms (groups 4 and 5) profile the culture in their organizational units. Each respondent sorted the 54 items into nine categories on the basis of how much each attribute characterized the focal organization; that is, individuals described their organization's culture, not their personal preferences. We performed a principal components analysis and varimax rotation using those data, again retaining items with loadings greater than .40 . Table 3 shows the factor loadings for the 26 items that loaded cleanly on factors retained on the basis of a scree test.

In this instance, seven clearly defined factors emerged. An inspection of the two factor analyses reveals that five of the eight factors shown in Table 1 are replicated almost exactly - innovation, outcome orientation, aggressiveness, detail orientation, and team orientation. Sixteen of the 20 items shown in Table 3 that are also in Table 1 load on the same factors. The nonreplication of the other three individual preference dimensions (supportiveness, emphasis on rewards, and decisiveness) seems to result from a lack of inclusion of the same items. Although direct comparison of the factor structures could be misleading because of the different stem questions, overall there appears to be good comparability between cultures as defined by individual preferences and actual organizational descriptions. The results of the factor analyses suggest that the OCP can provide a reasonable mapping of organizational culture.

\section{Person-Organization Fit and Individual Outcomes}

The evidence suggests that the 54 statements represent one possible approach to depicting culture, but an important question remains: Is personorganization fit systematically related to relevant organizational outcomes such as satisfaction, commitment, and turnover? Table 4 shows the correlations between person-organization fit and a set of outcome and control variables. The correlation between an individual's preferences and a firm's characteristics across the entire set of 54 items measures person-organization fit.

Of central interest are the correlations between person-organization fit and normative commitment $(r=.25, p<.01)$, overall job satisfaction $(r=$ $.35, p<.01)$, and intent to leave an organization $(r=-.37, p<.01)$. These relationships suggest clearly that high person-organization fit as measured at time 1 , when respondents originally entered their firms, is associated with high positive affect and a low intent to leave at time 2, a year later. Person- 


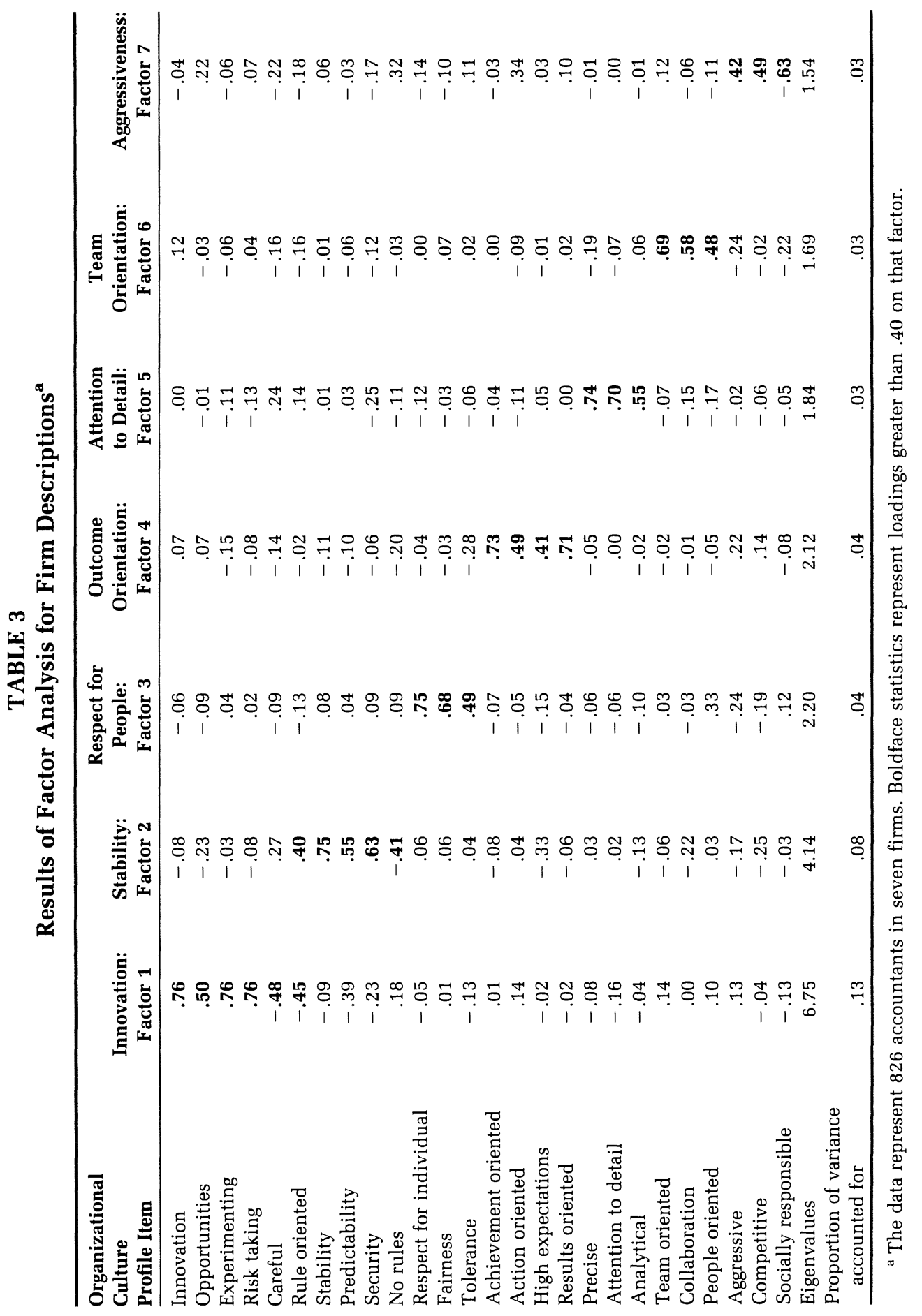




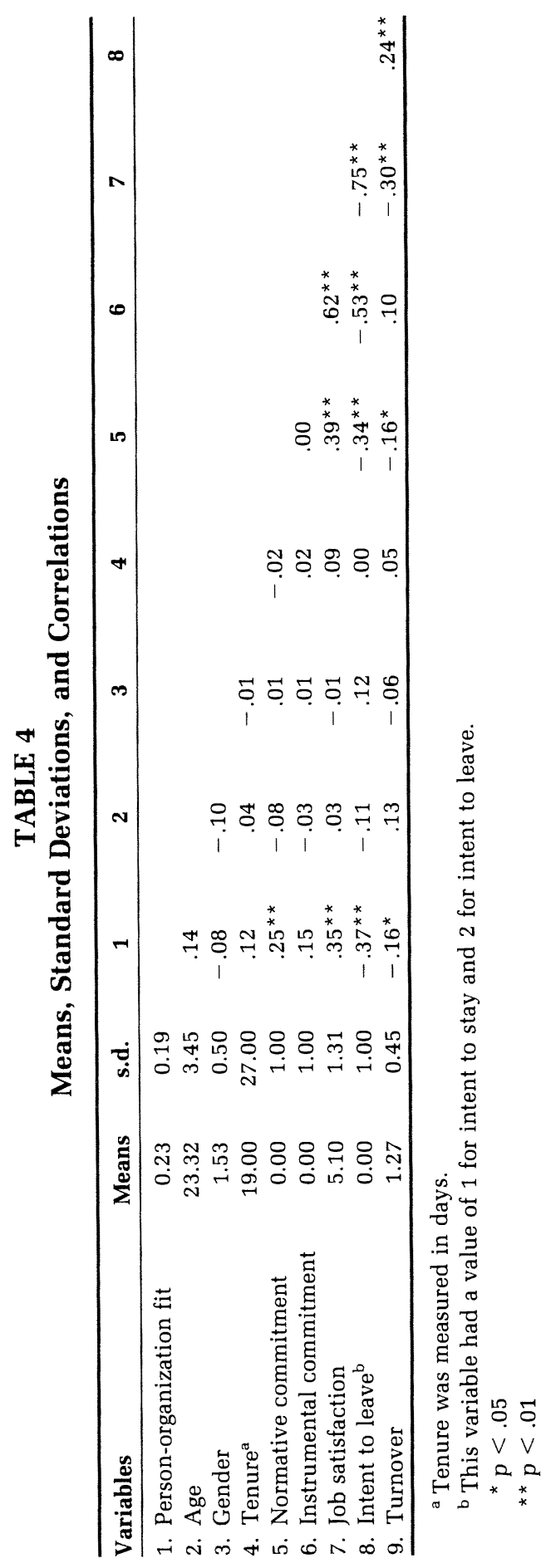


TABLE 5

Results of Regression Analysis ${ }^{a}$

\begin{tabular}{lcccc}
\hline Variables & $\begin{array}{c}\text { Normative } \\
\text { Commitment }\end{array}$ & $\begin{array}{c}\text { Instrumental } \\
\text { Commitment }\end{array}$ & $\begin{array}{c}\text { Job } \\
\text { Satisfaction }\end{array}$ & $\begin{array}{c}\text { Intent to } \\
\text { Leave }\end{array}$ \\
\hline $\begin{array}{l}\text { Person- } \\
\quad \text { organization fit }\end{array}$ & $.28^{* *}$ & -.07 & & \\
Age & -.11 & -.06 & $.36^{* *}$ & $.36^{* *}$ \\
Gender & -.04 & -.11 & -.05 & -.04 \\
Tenure & .01 & .06 & -.01 & .12 \\
Adjusted $R^{2}$ & .06 & & .08 & .01 \\
$F$ & $2.62^{*}$ & n.s. & .10 & .12 \\
\hline
\end{tabular}

${ }^{\text {a }}$ Entries represent standardized regression coefficients.

${ }^{*} p<.05$

$* * p<.01$

organization fit is not significantly related to either age or gender; however, in order to insure that these variables were not affecting the bivariate relationships, we included them as controls in the regression equations. Again, the results, reported in Table 5, are straightforward. Person-organization fit is a significant predictor of normative commitment, job satisfaction, and intentions to leave, independent of age, gender, and tenure.

Approximately 12 months after the collection of satisfaction and commitment measures, or 24 months after we assessed person-organization fit, we collected data on the employment status of all respondents. To assess whether person-organization fit would predict actual turnover 24 months later, we used survival analysis (Kalbfleish \& Prentice, 1980). Several recent papers (e.g., Fichman, 1988; Morita, Lee, \& Mowday, 1989; Peters \& Sheridan, 1988) have demonstrated the appropriateness of survival analysis for turnover research. This technique takes explicit account of time in the analysis of turnover and corrects for right censoring in the data. Table 6 presents these findings.

To determine whether person-organization fit has an effect on staying with a firm, the log likelihood of the base equation (model 1) was compared to the log likelihood of model 2. The chi-square of this difference is statistically significant $\left(\chi^{2}=8.69, p<.01\right)$, indicating that person-organization fit positively predicts the probability of a person's staying with a firm. Although the form of the relationship between person-organization fit and staying is nonlinear, an individual with a perfect fit score would be predicted to stay approximately twice as long as would be predicted using the base model alone. Similarly, an individual with a very high negative fit score would be predicted to stay about half as long as would be predicted with the base model. ${ }^{2}$

${ }^{2}$ For any respondent in this group, the predicted time of staying can be calculated by multiplying the exponential of the coefficient for person-organization fit (.64 in this group) by each respondent's person-organization fit score. Thus, for a person who has a fit score of 1.0, the 
TABLE 6

Results of Survival Analysis

\begin{tabular}{|c|c|c|c|c|}
\hline \multirow{2}{*}{$\begin{array}{l}\text { Independent } \\
\text { Variables } \\
\end{array}$} & \multicolumn{2}{|l|}{ Model 1} & \multicolumn{2}{|l|}{ Model 2} \\
\hline & Parameter Estimates $^{\mathbf{a}}$ & s.e. & Parameter Estimates $^{a}$ & s.e. \\
\hline Person-organization fit & & & $.64^{\star}$ & .29 \\
\hline Age & -.02 & .01 & -.02 & .01 \\
\hline Gender & .05 & .10 & .05 & .10 \\
\hline Scale parameter & .34 & & .34 & \\
\hline Logarithmic likelihood & -97.70 & & -93.36 & \\
\hline
\end{tabular}

${ }^{\text {a }}$ Estimates are unstandardized.

${ }^{*} p<.05$ for the chi-square value.

Figure 1 is a graph of the survival curve of the effects of personorganization fit on the likelihood of staying with an organization. We estimated the survivor function using Kaplan and Meier's nonparametric approach, as recommended by Tuma and Hannan (1984). Because it makes no assumptions about the functional form of the curve, the Kaplan and Meier estimator is one of the most common methods for assessing relationships when data are right-censored. Each of the descending legs indicates one or more instances of leaving. We divided the data into quartiles based on person-organization fit scores; Figure 1 shows the survival curves of the top and bottom quartiles. As shown, the curve for individuals with low personorganization fit scores has a steeper descent than the curve for high scorersthat is, low scorers are more likely to leave an organization than high scorers. Taken together, the data shown in Table 6 and Figure 1 offer compelling evidence for the positive effect of person-organization fit on an individual's staying with an organization.

Although it is not reported in detail, in addition to the measurement of person-organization fit, we obtained an assessment of person-job fit. Following the approach of Caldwell and O'Reilly (1990), we conducted a job analysis for the position held by all the entry-level accountants (group 1). We obtained a profile consisting of 60 competencies using six subject-matter experts from each of the eight firms. The reliability of this job profile across raters and within firms, assessed using a variation of the Spearman-Brown general prophecy formula, was quite high (.97). Entering accountants also provided a self-assessment using the same 60 competencies, and a personjob fit score was computed (average $r=.27$, s.d. $=14$ ). We then included this score in the analyses shown in Table 5 and as a control variable in the

calculation would be $\mathrm{e}^{(.64 \times 1)}=1.89$. Conversely, for a person with the lowest possible personorganization fit score $(-1)$, the calculation would be $\mathrm{e}^{(.64 \times-1)}=.53$. The interpretation is that with a perfect score on person-organization fit, an individual is likely to stay twice as long as we would have predicted without having information about their score. Conversely, a person with the lowest possible person-organization fit score will stay approximately half the time we would have predicted without knowing their score. 


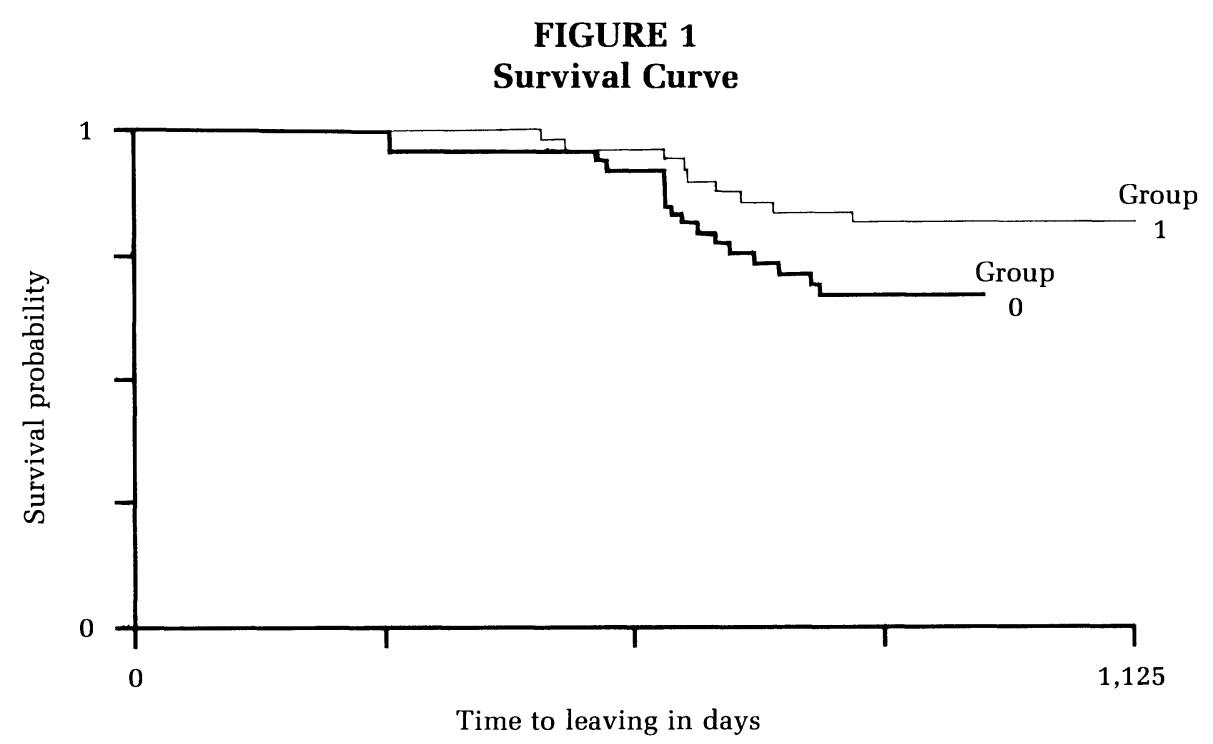

Group 0 had the lowest 25 percent of scores on the person-organization fit measure. Group 1 had the highest 25 percent of scores on the person-organization fit measure.

survival analysis. Although person-job fit did have some independent effects on job satisfaction and intent to leave, it had no impact on the person-culture fit relationships reported. The simple correlation between person-job and person-organization fit was .16 (n.s.). Thus, person-organization fit has quite independent effects on commitment, job satisfaction, and turnover.

\section{DISCUSSION}

Overall, the results presented here offer strong support for the validity of assessment of person-organization fit on the basis of value congruency. The results suggest that the Organizational Culture Profile shows reasonable reliability and convergent-discriminant validity. As results shown in Table 2 indicate, individual variations in preferences for different organizational cultures are associated with interpretable differences in personality characteristics. The structure underlying individual preferences (Table 1) also appears comparable to the structure underlying the culture in a selection of firms (Table 3).

The comparatively large number of values examined here also provides a fine-grained evaluation of organizations' cultures. As Chatman (1988) demonstrated, even organizations that appear highly similar, such as accounting firms as a group, may vary widely in their underlying value structures. Although there may be characteristic similarities in cultures within industries (e.g., Burns \& Stalker, 1961), use of a Q-sort approach allows for the identification of contrasts within and across organizations.

The factor analytic results provide a basis for future research. In view of 
those results, one general hypothesis might be that organization's cultures tend to be similar when the organizations are in relatively homogeneous industries and thus have similar sizes, structures, levels of technological maturity, personnel configurations, regulatory demands, and orientations. Conversely, the cultures of firms in heterogeneous industries may be less similar. Our factor analytic results would be especially useful for addressing this hypothesis because they allow assessment of differences in both factor patterns across industries and the mean values of particular firms on each relevant factor. For example, there may be greater variation on the innovation factor within a high-technology industry than within the public accounting industry. Previous researchers have conducted a similar kind of analysis of cultural factors across nations (Hofstede, Neuijen, Ohayv, \& Sanders, 1990).

The results reported here also suggest that person-organization fit may provide meaningful insights into individuals' adjustments to organizations (e.g., Holland, 1985; Louis, 1980). The predictive validity shown in Tables 4 through 6 is evidence of this potential. Measures of person-organization fit at time 1 were significantly related to individual commitment and satisfaction approximately 12 months later. Interestingly, person-culture fit is related to normative, value-based commitment but not to instrumental, compliancebased commitment. Caldwell and colleagues (1990) showed that normative commitment is often associated with firms with strong cultures. Researchers have often suggested that high commitment and satisfaction are outcomes of high person-organization fit (e.g., Kilmann et al., 1986; Ouchi \& Wilkins, 1985), but little empirical evidence of this association has been available. The lack of a significant correlation between congruence and instrumental commitment here is not surprising, given that our measures of congruence are predicated on fit between individual preferences and organizational values rather than on specific attributes of extrinsic rewards (Meyer \& Allen, 1984).

Of perhaps more practical importance is the association between person-organization fit and turnover almost 24 months later (Table 6). Recall that new accountants completed the OCP during their first few days with their organizations. We then compared individual preferences for a particular organizational culture to an organizational profile provided by a set of experienced organizational members. The degree to which individual preferences matched organizational realities was predictive of turnover two years later. Although some authors have questioned whether the strength of an organization's culture can be measured (Saffold, 1988), others have argued that strong agreement among organizational members about a few central norms or values defines an organizational culture (e.g., Enz, 1988; O'Reilly, 1989; Rousseau, 1990). These results seem to support that view.

In this regard, the OCP appears useful. First, as recent advances in the study of person-situation interaction have suggested, a Q-sort approach provides an idiographic assessment of the unique patterning of a large number of defining attributes for individuals and organizations. In the case of organ- 
izational culture, such a broad assessment would allow organizations to screen candidates against the organizational attributes that are most relevant to their personal values, not against some general rating of a few values that may not be personally important. In this respect, the profile comparison approach is simply a formalization of the logic of fit we use in everyday life. We ask "Will person $\mathrm{X}$ fit in situation $\mathrm{Y}$ ?" This is genuinely a question about person-situation congruence, not a main effect. We are not interested in how the person will do in situations $\mathrm{A}$ and $\mathrm{B}$ or whether person $\mathrm{Z}$ will fit in situation $\mathrm{Y}$. To answer such questions, we must know what a situation demands and how an individual's competencies and preferences fit a specific situation. This is precisely the information the profile comparison process yields. Most models of fit assess individual and environmental characteristics separately and then combine the two independent variables to predict behavior and attitudes (e.g., Joyce, Slocum, \& Von Glinow, 1982); the profile comparison process, however, provides a direct evaluation of the simultaneous effects of person and situation. The process assesses the relative salience and configuration of characteristics within individuals and then permits a comparison across situations. By evaluating the individual and situation on items that are relevant to both, the process is similar to what Wright and Mischel (1987) referred to as the "competency demand hypothesis." This method also permits individuals to hold values that may, in a broad sense, be conflicting. Both Ashforth and Mael (1989) and Swidler (1986) noted that value conflicts are common in organizations and are not measurable with more restrictive approaches.

In earlier studies, the idea of fit, although important, has remained elusive. As Rynes and Gerhart (1990) pointed out, most discussions of fit have implied something more than a simple match of an individual to a job's requirements and have frequently invoked notions of "chemistry" or finding the "right type" of person. In a study of recruiting M.B.A. graduates, they showed that firm-specific characteristics had significant impacts on recruiters' judgments beyond general employability attributes such as grade point averages and previous accomplishments. The results of the present study are consistent with those findings and suggest the fit of firm-specific and individual values may underlie earlier discussions of chemistry. Controlling person-job fit did not affect the results for person-culture fit as assessed here. Both are relevant. For an individual to be satisfied and attached to an organization, the person may need both task competency and a value system congruent with the central values of the organization. As for the organization, it needs to select people who fit a given situation, which is likely to include some combination of task and cultural requirements. Failure to fit on either dimension may reduce employees' satisfaction and commitment and increase the likelihood of their leaving.

The results of this study can contribute to future research in a number of ways. First, as organizational researchers continue to debate the importance of congruence between individuals and situations, these results demonstrate that a widely used tool for assessing personality can be adapted to 
provide comparable measures of persons and situations. The development of such methods can allow for research in a number of areas where fit to a job, occupation, or organization is conceived as either an important causal or outcome variable. Second, and more substantive, this research provides an empirically based definition of the pattern of values that define organizational culture. Although further validation of this approach to culture is necessary, the relatively consistent patterns of the individual preferences for values and the observation of those values in organizations suggests that the pattern defining organizational culture is relatively robust. Third, and perhaps of greatest importance, these results demonstrate that the fit between an individual's preference for a particular culture and the culture of the organization the person joins is related to commitment, satisfaction, and turnover. This study and others like it can help clarify both the nature of organizational culture and the impact of cultures on individuals.

\section{REFERENCES}

Albert, S., \& Whetten, D. 1985. Organizational identity. In L. L. Cummings \& B. M. Staw (Eds.), Research in organizational behavior, vol. 7: 263-295. Greenwich, CT: JAI Press.

Ashforth, B., \& Mael, F. 1989. Social identity theory and the organization. Academy of Management Review, 14: 20-39.

Barley, S. 1983. Semiotics and the study of occupational and organizational cultures. Administrative Science Quarterly, 28: 393-413.

Barley, S., Meyer, G., \& Gash, D. 1988. Cultures of culture: Academics, practitioners, and the pragmatics of normative control. Administrative Science Quarterly, 33: 24-60.

Bem, D., \& Allen, A. 1974. On predicting some of the people some of the time: The search for cross-situational consistencies in behavior. Psychological Review, 81: 506-520.

Bem, D., \& Funder, D. 1978. Predicting more of the people more of the time: Assessing the personality of situations. Psychological Review, 85: 485-501.

Block, J. 1978. The Q-sort method in personality assessment and psychiatric research. Palo Alto, CA: Consulting Psychologists Press.

Block, J., Block, J., \& Morrison, A. 1981. Parental agreement-disagreement on child rearing orientations and gender-related personality correlates in children. Child Development, 52: 965-974.

Brewer, M. B. 1979. In-group bias in the minimal intergroup situation: A cognitive-motivational analysis. Psychological Bulletin, 86: 393-400.

Brief, A., \& Roberson, L. 1989. Job attitude organization: An exploratory study. Journal of Applied Social Psychology, 19: 717-727.

Burns, T., \& Stalker, G. 1961. The management of innovation. London: Tavistock Publications.

Caldwell, D., \& O'Reilly, C. 1990. Measuring person-job fit using a profile comparison process. Journal of Applied Psychology, 75: 648-657.

Caldwell, D., Chatman, J., \& O’Reilly, C. 1990. Building organizational commitment: A multifirm study. Journal of Occupational Psychology, 63: 245-261.

Chatman, J. 1988. Matching people and organizations: Selection and socialization in public accounting firms. Unpublished doctoral dissertation, Walter A. Haas School of Business, University of California, Berkeley.

Chatman, J. 1989. Improving interactional organizational research: A model of personorganization fit. Academy of Management Review, 14: 333-349. 
Cooke, R., \& Rousseau, D. 1988. Behavioral norms and expectations: A quantitative approach to the assessment of organizational culture. Group and Organizational Studies, 13: 245-273.

Davis, S. 1984. Managing corporate culture. Cambridge, MA: Ballinger.

Davis-Blake, A., \& Pfeffer, J. 1989. Just a mirage: The search for dispositional effects in organizational research. Academy of Management Review, 14: 385-400.

Deal, T., \& Kennedy, A. 1982. Corporate cultures. Reading, MA: Addison-Wesley.

Diener, E., Larsen, R., \& Emmons, R. 1984. Person $\times$ situation interactions: Choice of situations and congruence response models. Journal of Personality and Social Psychology, 47: 580_ 592.

Downey, H., Hellriegel, D., \& Slocum, J. 1975. Congruence between individual needs, organizational climate, job satisfaction and performance. Academy of Management Journal, 18: 149-154.

Enz, C. 1988. The role of value congruity in intraorganizational power. Administrative Science Quarterly, 33: 284-304.

Fichman, M. 1988. Motivational consequences of absence and attendance: Proportional hazard estimation of a dynamic motivation model. Journal of Applied Psychology, 73: 119-134.

Geertz, C. 1973. The interpretation of cultures. New York: Basic Books.

Gough, H., \& Heilbrun, A. 1980. The Adjective Check List manual. Palo Alto, CA: Consulting Psychologists Press.

Gouldner, A. 1954. Patterns of industrial bureaucracy. New York: Free Press.

Graham, W. 1976. Commensurate characterization of persons, groups, and organizations: Development of the Trait Ascription Questionnaire (TAQ). Human Relations, 29: 607-622.

Hackman, J. R., \& Oldham, G. 1980. Work redesign. Reading, MA: Addison-Wesley.

Harrison, J., \& Carroll, G. 1991. Keeping the faith: A model of cultural transmission in formal organizations. Administrative Science Quarterly, 36: in press.

Hofstede, G., Neuijen, B., Ohayv, D., \& Sanders, G. 1990. Measuring organizational cultures: A qualitative and quantitative study across twenty cases. Administrative Science Quarterly, 35: $286-316$.

Holland, J. L. 1985. Making vocational choices (2d ed.). Englewood Cliffs, NJ: Prentice-Hall.

Joyce, W., \& Slocum, J. 1984. Collective climate: Agreement as a basis for defining aggregate climates in organizations. Academy of Management Journal, 27: 721-742.

$\rightarrow$ Joyce, W., Slocum, J., \& Von Glinow, M. 1982. Person-situation interaction: Competing models of fit. Journal of Occupational Behavior, 3: 265-280.

Kalbfleisch, J., \& Prentice, R. 1980. The statistical analysis of failure time data. New York: Wiley.

Kenrick, D., \& Funder, D. 1988. Profiting from controversy: Lessons from the person-situation debate. American Psychologist, 43: 23-35.

Keon, T., Latack, J., \& Wanous, J. 1982. Image congruence and the treatment of difference scores in organizational choice research. Human Relations, 35: 155-165.

Kilmann, R. 1984. Beyond the quick fix. San Francisco: Jossey-Bass.

Kilmann, R., Saxton, M., \& Serpa, R. 1986. Gaining control of the corporate culture. San Francisco: Jossey-Bass.

Kunin, T. 1955. The construction of a new type of attitude measure. Personnel Psychology, 8: $65-78$.

Lamiell, J. 1981. Toward an idiothetic psychology of personality. American Psychologist, 36: $276-289$. 
Lofquist, L., \& Dawis, R. 1969. Adjustment to work. New York: Appleton-Century-Crofts.

Louis, M. 1980. Surprise and sense making: What newcomers experience in entering unfamiliar organizational settings. Administrative Science Quarterly, 25: 226-251.

Louis, M. 1983. Organizations as culture-bearing milieux. In L. Pondy, P. Frost, G. Morgan, \& T. Dandridge (Eds.), Organizational symbolism: 186-218. Greenwich, CT: JAI Press.

Luthans, F., \& Davis, T. 1982. An idiographic approach to organizational behavior research: The use of single case experimental designs and direct measures. Academy of Management Review, 7: 380-391.

Martin, J., \& Siehl, C. 1983. Organizational culture and counterculture: An uneasy symbiosis. Organizational Dynamics, 12(1): 52-64.

Meir, E., \& Hasson, R. 1982. Congruence between personality type and environment type as a predictor of stay in an environment. Journal of Vocational Behavior, 21: 309-317.

Meyer, J. P., \& Allen, N. J. 1984. Testing the "side-bet" theory of organizational commitment: Some methodological considerations. Journal of Applied Psychology, 69: 372-378.

Moreland, R. 1985. Social categorization and the assimilation of "new" group members. Journal of Personality and Social Psychology, 48: 1173-1190.

Morita, J., Lee, T., \& Mowday, R. 1989. Introducing survival analysis to organizational researchers: A selected application to turnover research. Journal of Applied Psychology, 74: 280292.

Mount, M., \& Muchinsky, P. 1978. Person-environment congruence and employee job satisfaction: A test of Holland's theory. Journal of Vocational Behavior, 13: 84-100.

Nadler, D., \& Tushman, M. 1980. A model for diagnosing organizational behavior: Applying a congruence perspective. Organizational Dynamics, 9(3): 35-51.

Nunnally, J. C. 1978. Pychometric theory. New York: McGraw-Hill.

O'Reilly, C. A., III. 1977. Personality-job fit: Implications for individual attitudes and performance. Organizational Behavior and Human Performance, 18: 36-46.

O’Reilly, C. A., III. 1989. Corporations, culture, and commitment: Motivation and social control in organizations. California Management Review, 31(4): 9-25.

O'Reilly, C. A., III, Caldwell, D., \& Mirabile, R. 1990. More than a mirage: Dispositionsituation interaction as explanations of work behavior. Working paper, Walter A. Haas School of Business, University of California, Berkeley.

O'Reilly, C. A., III, \& Chatman, J. 1986. Organizational commitment and psychological attachment: The effects of compliance, identification, and internalization of prosocial behavior. Journal of Applied Psychology, 71: 492-499.

Ouchi, W. 1981. Theory Z. Reading, MA: Addison-Wesley.

Ouchi, W., \& Wilkins, A. 1985. Organizational culture. In R. Turner (Ed.), Annual review of sociology, vol. 11: 457-483. Palo Alto, CA: Annual Reviews.

Parsons, T. 1951. The social system. New York: Free Press.

Pervin, L. 1968. Performance and satisfaction as a function of individual-environment fit. Psychological Bulletin, 69: 56-68.

Peters, L., \& Sheridan, J. 1988. Turnover research methodology: A critique of traditional designs and a suggested survival model alternative. In K. Rowland \& G. Ferris (Eds.), Research in personnel and human resources management, vol. 6: 231-262. Greenwich, CT: JAI Press.

Peters, T., \& Waterman, R. 1982. In search of excellence. New York: Harper \& Row.

Rokeach, M. 1973. The nature of human values. New York: Free Press.

Rousseau, D. 1990. Quantitative assessment of organizational culture: The case for multiple 
measures. In B. Schneider (Ed.), Frontiers in industrial and organizational psychology, vol. 3: 153-192. San Francisco: Jossey-Bass.

Rynes, S., \& Gerhart, B. 1990. Interviewer assessments of applicant "fit": An exploratory investigation. Personnel Psychology, 43: 13-34.

Saffold, G. 1988. Culture traits, strength, and organizational performance: Moving beyond "strong" culture. Academy of Management Review, 13: 546-558.

Sampson, E. 1978. Personality and the location of identity. Journal of Personality, 46: 552568.

Schein, E. 1985. Organizational culture and leadership. San Francisco: Jossey-Bass.

Schneider, B. 1987. The people make the place. Personnel Psychology, 40: 437-453.

Selznick, P. 1949. TVA and the grass roots. Los Angeles: University of California Press.

Smircich, L. 1983. Concepts of culture and organizational analysis. Administrative Science Quarterly, 28: 339-359.

Spokane, A. 1985. A review of research on person-environment congruence in Holland's theory of careers. Journal of Vocational Behavior, 26: 306-343.

Springfield, A. 1988. An Aristotelian resolution of the idiographic versus nomothetic tension. American Psychologist, 43: 425-430.

Stephenson, W. 1953. The study of behavior: Q-technique and its methodology. Chicago: University of Chicago Press.

Stryker, E., \& Serpe, R. 1982. Commitment, identity salience, and role behavior: Theory and research example. In W. Ickes \& E. Knowles (Eds.), Personality, roles, and social behavior: 119-218. New York: Springer-Verlag.

Super, D. 1957. The psychology of careers. New York: Harper \& Row.

Swidler, A. 1986. Culture in action: Symbols and strategies. American Sociological Review, 51: $273-286$.

Terborg, J. 1981. Interactional psychology and research on human behavior in organizations. Academy of Management Review, 6: 569-576.

Tom, V. 1971. The role of personality and organizational images in the recruiting process. Organizational Behavior and Human Performance, 6: 573-592.

Trice, H., \& Beyer, J. 1984. Studying organizational cultures through rites and ceremonials. Academy of Management Review, 9: 653-669.

Tsui, A., \& O'Reilly, C. A., III. 1989. Beyond simple demographic effects: The importance of relational demography in superior-subordinate dyads. Academy of Management Journal, 32: $402-423$.

Tuma, N., \& Hannan, M. 1984. Social dynamics: Models and methods. Orlando, FL: Academic Press.

Wanous, J. P. 1977. Organizational entry: Newcomers moving from outside to inside. Psychological Bulletin, 87: 601-618.

Weiner, Y. 1988. Forms of value systems: A focus on organizational effectiveness and cultural change and maintenance. Academy of Management Review, 13: 534-545.

Weiss, H., \& Adler, S. 1984. Personality and organizational behavior. In B. M. Staw \& L. L. Cummings (Eds.), Research in organizational behavior, vol. 4: 1-50. Greenwich, CT: JAI Press.

Wilkins, A., \& Ouchi, W. 1983. Efficient cultures: Exploring the relationship between culture and organizational performance. Administrative Science Quarterly, 28: 468-481.

Wright, J., \& Mischel, W. 1987. A conditional approach to dispositional constructs: The local predictability of social behavior. Journal of Personality and Social Psychology, 53: 11591177. 


\section{APPENDIX \\ Organizational Culture Profile Item Set}

1. Flexibility

2. Adaptability

3. Stability

4. Predictability

5. Being innovative

6. Being quick to take advantage of opportunities

7. A willingness to experiment

8. Risk taking

9. Being careful

10. Autonomy

11. Being rule oriented

12. Being analytical

13. Paying attention to detail

14. Being precise

15. Being team oriented

16. Sharing information freely

17. Emphasizing a single culture throughout the organization

18. Being people oriented

19. Fairness

20. Respect for the individual's right

21. Tolerance

22. Informality

23. Being easy going

24. Being calm

25. Being supportive

26. Being aggressive
27. Decisiveness

28. Action orientation

29. Taking initiative

30. Being reflective

31. Achievement orientation

32. Being demanding

33. Taking individual responsibility

34. Having high expectations for performance

35. Opportunities for professional growth

36. High pay for good performance

37. Security of employment

38. Offers praise for good performance

39. Low level of conflict

40. Confronting conflict directly

41. Developing friends at work

42. Fitting in

43. Working in collaboration with others

44. Enthusiasm for the job

45. Working long hours

46. Not being constrained by many rules

47. An emphasis on quality

48. Being distinctive-different from others

49. Having a good reputation

50. Being socially responsible

51. Being results oriented

52. Having a clear guiding philosophy

53. Being competitive

54. Being highly organized

Charles A. O'Reilly III is a professor of organizational behavior in the Walter A. Haas School of Business, University of California, Berkeley, where he received his Ph.D. degree. His current research interests include studies of executive teams, CEO compensation, and person-job fit.

Jennifer A. Chatman is an assistant professor of organization behavior at Northwestern University. Her current research interests include studies of person-job and personorganization fit and the role of selection and socialization. She received her Ph.D. degree from the University of California, Berkeley.

David F. Caldwell is professor in the Leavey School of Business and Administration, Santa Clara University. His current research interests include studies of group demography and group process in product development teams. He received his Ph.D. degree from the University of California, Los Angeles. 